\title{
Educating Beyond Cultural Diversity: Redrawing the Boundaries of a Democratic Plurality
}

\author{
Sharon Todd
}

Published online: 9 December 2010

(C) Springer Science+Business Media B.V. 2010

\begin{abstract}
In this paper I draw some distinctions between the terms "cultural diversity" and "plurality" and argue that a radical conception of plurality is needed in order both to reimagine the boundaries of democratic education and to address more fully the political aspects of conflict that plurality gives rise to. This paper begins with a brief exploration of the usages of the term diversity in European documents that promote intercultural education as a democratic vehicle for overcoming social conflict between different cultural groups. In contradistinction to these usages, this paper calls for a more robust conception of plurality, one that does not simply denote membership in different cultural groupings but is rooted in the human condition and based on a conception of uniqueness. Following the work of Hannah Arendt and feminist philosopher Adriana Cavarero, I explore how the appearance of unique beings in specific contexts can be understood as an eminently political act and I contend that such a view leads to a better educational understanding of conflict and contestation. The paper sketches the contours of democratic plurality along this line of thought and discusses how these new boundaries have implications for education's relation to democracy.
\end{abstract}

Keywords Hannah Arendt - Adriana Cavarero - Education - Diversity - Democracy · Politics · Europe $\cdot$ Uniqueness

\section{Introduction}

It seems almost commonplace to speak of diversity as a central aspect of educational initiatives concerned with promoting democracy, particularly those that focus on interculturalism as a means for addressing potential social conflict. But what is meant by the term "diversity" and how does it relate to democratic projects in education? In what follows, I draw some distinctions between the terms "cultural diversity" and "plurality" and argue that a radical conception of plurality is needed in order both to re-imagine the boundaries of democratic education and to address more fully the political aspects of

S. Todd $(\bowtie)$

Department of Education, Stockholm University, Frescativägen 54, 10691 Stockholm, Sweden e-mail: sharon.todd@ped.su.se 
conflict that plurality gives rise to. This paper begins with a brief exploration of the usages of the term diversity in European documents ${ }^{1}$ that promote intercultural education as a democratic vehicle for overcoming social conflict between different cultural groups. Here, it can be seen that cultural diversity is frequently synonymous with a view of individuals as the aggregate of their cultural attributes, a fact that prevents, in my view, adequate engagement with the very terms of conflict such educational endeavours seek to surmount. Instead, this paper calls for a more robust conception of plurality, one that does not simply denote membership in different cultural groupings but is rooted in the human condition and based on a conception of uniqueness. Indeed, following the work of Hannah Arendt and feminist philosopher Adriana Cavarero, I explore how the appearance of unique beings in specific contexts can be understood as an eminently political act and I contend that such a view leads to a better educational understanding of conflict and contestation. The paper sketches the contours of democratic plurality along this line of thought and discusses how these new boundaries have implications for education's relation to democracy.

\section{Intercultural Education: The "Problem" with Diversity}

The Council of Europe has been instrumental in promoting intercultural education as part of its larger commitment to education for democracy. Although often treated under separate headings and appearing under a variety of mandates (concerning religion, human rights, and democracy), there is a forging of interests around interculturalism where it concerns the question of diversity. Diversity, in a number of documents and conference presentations given at the behest of the Council, frequently is depicted in rather broad terms: "culture, gender, age, social situation, geographical origin, interests, beliefs, physical and intellectual characteristics, etc. There are differences between individuals and differences between groups" (Batelaan 2003, p. 2). ${ }^{2}$ Diversity here is presented-at least initially-in its broadest possible meaning and the "etc." seems to indicate a seemingly endless list of our differences. However, in most of the documents examined, including this same one, this breadth does not hold entirely in relation to their stated intercultural mission. The question about to how to "manage" diversity is posed, since in certain countries "the population is becoming more and more diverse in terms of ethnicity, culture, languages, religions and other value orientations" (Batelaan 2003, p. 4). Diversity is thus rendered in terms of attributes or characteristics of differences. Diversity is shorthand for naming precisely those differences that need to be "managed" since they create the conditions for conflicts to arise. Thus what undergirds such articulations of cultural diversity is the assumption that diversity is a problem, a source of social tension, that needs to be remedied by intercultural education.

Indeed here and elsewhere intercultural education is seen to be a "conflict prevention device" (Leclerq 2002, p. 7; see Bourquin 2003), one of the "coping strategies" (Batelaan 2003, p. 3) needed in Europe so that we can learn to live together more harmoniously. The specifically political and democratic aspects of intercultural education revolve around the recognition of "differences" and around the incorporation "of all pupils into the plural

\footnotetext{
${ }_{1}$ I have taken only a small sample of position papers and singled authored texts and presentations used for informing educational policy at the Council of Europe.

2 Another instance of this broad definition can be found in a glossary in Religious Diversity and Intercultural Education: A Reference Book for Schools (Council of Europe, 2007), whereby it reads: "The presence of a variety of differences; these may be approaches, views, lifestyles, practices and attitudes that are different from each other, but exist in the same place, revealing difference. Diversity in the classroom relates to heterogeneous academic skills, linguistic skills and background, culture or religion” (p. 200).
} 
society where they dwell and lead their lives" in order to combat discrimination (Leclerq 2002, p. 4). Moreover, the specifically democratic aspects of intercultural education come to the fore in the articulation of democracy as being "characterised by pluralism (doing justice to diversity)" (Batelaan 2003, p. 3). In this context, democracy is about advocating an "ism" - an orientation, ideology, substantive theory-which works toward a policy of inclusion; that is, democracy does the work of incorporating into its fold the many differences to be found at the societal level. In particular, the documents paint a picture of democracy where pluralism-along with human rights and the rule of the law-are foundational values to be respected by all, irrespective of our diverse make-up (Council of Europe 2007). Thus the emphasis on intercultural education seeks to create conditions for "dealing" with diversity in such a way that they, in turn, serve the democratic arrangements of European societies. Intercultural education in this sense is seen as an intervention into the possible eruption of conflict that diversity always seems to threaten: "intercultural education is capable of felicitously staving off the conflicts that alas often seem to have become the ordinary lot of our societies" (Leclerq 2002, p. 8). Not surprisingly perhaps, the major strategy employed by intercultural education is dialogue. Dialogue is cast as "indispensable" (Batelaan 2003, p. 3), it is to be made "meaningful in order to obtain direct results and/or to solve problems" (ibid.), and it is "an educational instrument to avoid conflict" (Council of Europe 2007). Thus, what we have here is a view of intercultural education that promotes democracy through a dialogue that seeks to avert conflict. What this means, then, is not only that diversity as a set of cultural attributes is seen to be problematic to European social cohesion, but that the way in which European societies need to "deal" with this problem is to promote a non-conflictual view of democracy itself.

This connection raises two issues: First, that democracy is tied to a conception of diversity that not only needs to be "handled" but that it does so in a way that turns a person into an aggregate of her cultural attributes: she bears these attributes like a mantle into encounters with others as though they stand for who she is. There is thus a certain ontology that is operating here which serves to pin the subject down to general categories of culture. By this I mean that although some lip service might be paid to "personal difference" (Leclerq 2002, p. 4; Bourquin 2003, p. 32), the term nonetheless refers to an abstract individual that happens to embody recognizable cultural differences. So while differences might be "personal," they are in no way conceived as unique or particular. Thus, the individual becomes a generalized figure read through her attributes. Secondly, dialogue is thereby concerned with the ways these generalized individuals can communicate across their cultural differences. Dialogue is positioned as the necessary tool for remedying the competing worldviews, beliefs, knowledges, and positions to which cultural differences give rise. Dialogue therefore cannot be about particular persons engaging as unique, embodied individuals but only as 'cultural' subjects (i.e., those who represent a particular cultural community) who solve problems in the service of democracy. Thus the issue here is how democracy itself-if it is indeed serviced by this conception of dialogue-is rendered as a social arrangement that smoothes over tensions brought about by cultural differences. In this light, democratic dialogue becomes a social convention or procedure that seems to have little to do with the specifically political dimensions of conflicts themselves.

\section{Shifting From Diversity to Plurality and From Dialogue to Narrative}

I take, then, as my point of departure for the rest of this paper, the idea that a shift away from the language of diversity so present in educational discussions about interculturalism 
is needed in order to reframe better the democratic aspects of education. What is chiefly evident in the above descriptions of diversity is that what makes "us" diverse is rooted in an understanding of what individuals represent and not in an understanding of who they are. This distinction between the "what" of representation and the "who" of unique persons seems to me crucial if the project of democracy is going to be felt and lived as a specifically political project that is not reduced to social relations, social categories, and society's demands. Unlike Dewey (1916/1966), for example, who conceives democracy as a form of "associated living," what this paper explores further is the idea that the very nature of the political rests upon something other than our social arrangements and our understanding of persons as 'what' they represent. Although Dewey's conception implies that democracy is a social arrangement that engages living beings in their situatedness and contingency, it nevertheless seems to suggest that democracy is not directly tied to an understanding of the political as a "dimension of antagonism... constitutive of human societies" (Mouffe 2005, p. 9). What I am proposing here is that we can attend better to the specifically antagonistic aspects of democracy if we shift our focus from diversity to plurality. This plurality, following Arendt and Cavarero, requires acknowledging a unique "who" that emerges in the context of a narrative relation that not only cannot be reduced to social categorizations, but that itself is political. In their view, as we shall see, it is the act of narration, and not dialogue, which holds political potential. Thus, for the remainder of the paper, I explore more fully this conception of uniqueness in plurality and the role narrative plays therein in order to rethink the terms through which democratic education can create spaces not in which to "deal" with conflict, but in and through which to articulate it.

\section{The Ontology of Plurality}

Shifting the focus to an ontology of plurality, means shifting focus from a singular, abstract view of the individual, to a view that sees plurality as part of the human condition. ${ }^{3}$ To depict this as an "ontology", however, would seem to raise a red flag for many who seek to move beyond the discourses of modernist philosophical conceptions of "Man" in which ontology by its very nature seeks to capture individual differences within a universalizing and essentialist conception of being. However, Cavarero (2005), drawing on Hannah Arendt, uses this term to depict the rethinking that occurs when plurality is introduced into the logic of the human condition as an inevitable aspect of one's being in the world with others. On this line of thought, ontology signals the facticity of plurality without granting it any substantive content. That is, Cavarero deploys this term (somewhat ironically) to suggest that plurality, while inevitable to being, nonetheless escapes concrete definition. Plurality thus subverts conventional understandings of ontology insofar as it grants a central place to the uniqueness of persons as they come together in specific contexts.

No one is perhaps more adamant about the role that plurality plays in political life than Hannah Arendt. Critical of how philosophers have traditionally handled the question of plurality in politics, Arendt claims that they operate with "commonalities" that have been abstracted from "an absolute chaos of differences" (Arendt 2005, p. 93). Universal 'Man'

\footnotetext{
${ }^{3}$ Note here that I am using Arendt's terminology of the human condition as opposed to falling back on notions of human nature or even the human subject. One reason for doing so is to highlight the ways in which Arendt and Cavarero see the facticity and materiality of plurality as an unavoidable and inevitable aspect of being in the world.
} 
has thereby become the key term in depictions of political equality and freedom and in so doing has denied the fact that "politics deals with the coexistence and association of different men" (ibid.). Thus in the predication of political organization along the lines of universalism or generalization, "any original differentiation is effectively eradicated, in the same way that the essential equality of all men, insofar as we are dealing with man, is destroyed" (Arendt 2005, p. 94). In order, therefore, to begin to reconsider the political dimension of existence, we need to stop "playing God," as Arendt puts it, in defining what man is, and focus instead on who men are. ${ }^{4}$

This does not mean, however, that "who men are" can be defined in the abstract-this would simply revert back to the very universalism that Arendt seeks to move away from. Unlike liberalism's abstract individual, the who-ness of which Arendt writes is a uniqueness that emerges in a particular situation and context. Specifically, it is a uniqueness that appears in the in-between space with other human beings; it reveals itself in speech and action. "This revelatory quality of speech and action comes to the fore where people are with others and neither for nor against them - that is, in sheer human togetherness" (Arendt 1959, p. 160). However, as she goes on to emphasize here and elsewhere, living human beings are not simply appearances like other objects in the world, but they actively disclose themselves in their encounters with others: "To be alive means to be possessed by an urge toward self-display... Living things make their appearance like actors on a stage set for them" (Arendt 1978, p. 21). In this sense, the living subject both appears to others and does so through her own activity. Thus, human beings are not simply distinct, but they distinguish themselves; that is, they actively put forth their who-ness in the very gesture of their words and deeds.

Speech and action, therefore, open up the possibility for disclosure. "This disclosure of the 'who' in contradistinction to the 'what' somebody is-his qualities, gifts, talents, and shortcomings, which he may display or hide-is implicit in everything somebody says and does" (Arendt 1959, p. 159). What this means is that the uniqueness of the individual speaker and actor is revealed through the very act of utterance and the deeds committed. This revelation, then, is not connected to the content of what one says, but to the presence that is implicit in the saying. Not unlike Levinas (1998/1974) in this regard, who makes a distinction between the Said and Saying, Arendt is adamant that it is a unique presence that announces itself through the space in-between people. That is, it is in the action of saying that one's presence makes itself felt, not in the actual words one speaks. In an important sense, because uniqueness emerges through the events of speaking and acting, Arendt forecloses the possibility of viewing uniqueness as some sort of essence; it is instead always contextual and specific. Thus, although we might bear certain cultural differences that shape the content of our speech, it is our material uniqueness as embodied, speaking subjects that constitutes the condition of plurality. As Arendt puts it, "human plurality is the paradoxical plurality of unique beings" (1959, p. 156).

What is important for my purposes here is that Arendt sees this space of disclosure as a specifically political space-one that is eminently contextual. As Cavarero writes, "actively revealing oneself to others, with words and deeds, grants a plural space and therefore a political space to identity-confirming its exhibitive, relational and contextual

\footnotetext{
4 While not wanting to sidestep the problematic usage of the terms man and men in Arendt's texts, I do want to retain this usage for the moment in order to highlight the historical fact that it has been Man as universal-and men in the plural—which has guided thinking in political philosophy. When I address the work of the Italian feminist philosopher, Adriana Cavarero, I shift my language and follow her usage accordingly.
} 
nature" (2000, p. 22). For Arendt, it is the hero of classical mythology that provides the quintessential model for this coinciding of being and appearing. As Cavarero puts it, the hero shows "the same exhibitive action that comes to characterize the agonistic spirit of the democratic polis" (ibid.). The hero, in other words, both appears and discloses, and by doing so creates agonistic tensions with those others with whom he is in interaction. There is a non-substitutability to the hero-he (most often a he) appears to others at the moment he discloses his own identity. On this account, then, his is not an identity that is different because he holds different attributes or qualities or opinions, but because his uniqueness asserts itself as a freedom. "If anything, for Arendt, the pluralism of opinions functions as an indirect proof of a plurality of unique beings that is translated into a multiperspective disposition of their worldview. In other words, for Arendt, the political lies entirely in the relational space between human beings who are unique and therefore plural" (Cavarero 2005, p. 192).

Arendt is therefore critical of attempts to do away with this relational space and of any efforts to unite plurality under the banner of humanity: "In the idea of world history, the multiplicity of man is melted into one human individual which is then also called humanity. This is the source of the monstrous and inhuman aspect of history..." (Arendt 2005 , p. 95). She sees this relational space as central to political life and is resistant to even well-intentioned attempts to recuperate a notion of democracy that does away with the inevitable antagonism, or "calamities," that arises out of plurality:

The calamities of action all arise from the human condition of plurality, which is the condition sine qua non for this space of appearance which is the public realm. Hence to do away with this plurality is always tantamount to the abolition of the public realm itself. The most obvious salvation from the dangers of plurality is monarchy, or one-man-rule, in its many varieties, from outright tyranny of one against all to benevolent despotism and to those forms of democracy in which the many form a collective body so that the people "is many in one" and constitute themselves as a "monarch". (Arendt 1959, p. 197)

Thus her view of democracy is instead more closely tied to the agonistic polis than it is to the idea of the demos. As opposed to constructing a unified ideal of the people, the polis by contrast is a relational, narrative space. Within the polis, there is agonism; it is "a space of confrontation" (Cavarero 2005, p. 185) through which individuals make their unique appearance.

There exists, for Arendt, a certain unpredictability with respect to the consequences of our speech and action as they are storied through narrative. The unpredictability is ushered in first by the fact that the actor is "not merely a 'doer' but always and at the same time a sufferer" (Arendt 1959, p. 169). In this, the actor sets a story in motion-through word or deed-that is composed of its consequent deeds and sufferings. That is, the consequences

\footnotetext{
5 Biesta (2010) has recently outlined the importance of what he calls "political existence" for rethinking the relationship between democracy and education through Arendt's focus on freedom. In this, he suggests that there is a possibility of "learning from" political existence and hence sees that there is an inherent educational dimension at stake. However, in slight distinction from Biesta, I am more interested in emphasising the contextual spaces of plurality through which unique existences make their appearance. There is thus, in my view, an inevitable messiness and contestation in the very appearance of "who" someone is, which needs to be brought to the fore in any rethinking of democracy and education. If there is an implicit pedagogical element in the public space of appearances, it lies, in my view, in the transformation of existence made possible through speech and action and in the conflicts and tensions and that the condition of plurality inevitably brings.
} 
of who we are as we speak are boundless and as such occasion responses that in turn affect us. Secondly, there is an unpredictability to the story insofar as it leaves behind the intentions of the actor/speaker and becomes articulated in the voice of others. That is, the speaker/actor is not the author of her story, but the story gets made and retold by others, which rebound back to her, hitting her unawares (Arendt 1959, p. 171). ${ }^{6}$

While this emphasis on story and narrative might appear to be a detour in this discussion on democracy and politics, I focus on it here to give a sense of how Arendt conceives of political space as one that has narrative content. For Arendt, it is precisely this unpredictability of the story that can be related to the "revelatory character of speech and action" (Arendt 1959, p. 171). Here, the one who discloses herself does not know who she reveals to and with others. In this, narrative is unlike many dialogic models of democracy so prevalent in education. For instance, the deliberative model, largely based on Jürgen Habermas's ideas, centres on the capacity to communicate something to someone, and to respect the rules of discourse in coming to some kind of consensus about these competing articulations. Although Habermas himself finds parallels with Arendt in his development of a notion of dialogue as communicative rationality, Cavarero's gloss on a text of Habermas pinpoints the crucial difference:

For Arendt, what makes speech political is not signification, expression, or the communication of something, even if that "something" is the just, the useful, the good, or the bad. Rather, the political essence of speech consists in revealing to others the uniqueness of each speaker.... What Arendt calls "political" is in fact a space that is materially shared, whereupon those present show to one another, in words and deeds, their uniqueness and their capacity to begin new things. (Cavarero 2005, p. 189)

As Cavarero emphasizes, this relational space of politics is dependent upon others with whom one shares that space. One's uniqueness is not entirely known to oneself and therefore depends upon another to tell 'her' story back to her. Uniqueness, therefore, both emerges as a presence to which others respond, and requires that others return, as a gift, one's own sense of uniqueness. It is this back and forth narrative trajectory that is threatened when the one who speaks is seen to be merely an aggregate of her cultural background. The so-called democratic dialogue which is supposed to aid us in understanding each other across our differences, simply robs us of our uniqueness and therefore of these very differences. Paradoxically, dialogue turns differences into something that is incommunicable.

What Arendt shows us is that the relational space in-between us is not only fundamentally political but is also narrative in character. It is a space that is necessarily fraught with moments of agonism, since each of us is revealed and discloses herself differently. That we depend on others to hear and respond to our words and deeds, our stories, means that when we speak to others we risk also having to bear the story others have created about us, about who we are. Thus this exchange is also fraught with vulnerability and exposure, to use Cavarero's phrasing, which, to my mind, is the reason why conflict between us can

\footnotetext{
${ }^{6}$ As Natasha Levinson (2001) has pointed out, Arendt's idea of natality, of creating something new through speech and action, is paradoxical, insofar as each one of us is also confronted by others who may thwartand not simply enable-our political actions: "Natality is both what motivates political action and what mitigates against our actions having the intended effect" (p. 13). Thus, Levinson's views serve to complicate what some see as a relatively straightforward concept in Arendtian thought, and it shows, in my view, the necessary ambiguity that accompanies the appearance of uniqueness.
} 
be so painful. As Arendt says, each act of the speaker/doer occasions suffering, which makes politics also an eminently affective engagement with plurality.

However, Arendt, like Mouffe in this regard, does not collapse ontology into the political, but sees them as having a necessary relation. If, in other words, an ontology of plurality sets the condition for political agonism, what is political about this agonism is that it reveals itself through action and speech. As Cavarero puts it:

In other words, all human beings are unique, but only when and while they interact with words and deeds can they communicate to one another this uniqueness. Without such communication, without action in a shared space of reciprocal exhibition, uniqueness remains a mere ontological given - the given of an ontology that is not able to make itself political. (Cavarero 2005, p. 196)

Thus, shifting from an ontology of diversity to an ontology of plurality (in all its contingency) means having to reframe the relation between the political and "who" each of us is, as this appears across particular times and places. This further means not being able to deduce - or reduce - who someone is to a series of attributes that then determine (or at least shape) political action. Rather, the space of political action is one where the givenness of plurality becomes articulated, thus making these articulations contextual, specific and relational in character. In this view, the political becomes an articulation of differences - and the conflicts that inevitably arise from these differences-in local contexts. It is to this idea that I now turn.

\section{Political Space as an “Absolute Local”}

In capturing this new sense of political potential in Arendt, and in remaining faithful to her ontology of plurality, Cavarero develops a notion of the "absolute local" as a political space of relationality. In this, it offers a way of conceiving of the political-and, in my view, democracy - that takes into account the centrality of the contemporary status of global political conditions, where the identification of someone in terms of a single cultural community or nation is neither viable nor possible. In light of this globalization, Cavarero views politics as no longer being tied to a place, and in fact she sees Arendt's focus on the space of politics as a point of convergence with these current conditions. "Indeed, at stake is the basic principle of politics that Arendt understands as interaction and the sharing of a common space that is generated by interaction itself. The in-between regards a space, not a territory. Politics takes place, but it is not a place" (Cavarero 2005, p. 204). In this respect, "who" one is is not bound to a place, but to a space of relationality that exists between us, here and now, and as such gives a different sense of contextuality than that which we usually identify with fixed notions of where politics happens. On Cavarero's account, the local context of politics is "absolute" because it is

freed from the territoriality of place and from every dimension that roots it in a continuity. The absolute local is thus the name of a taking-place of politics that has no predefined borders, nor any fixed or sacred confines. It is not a nation, nor a fatherland, nor a land. It extends as far as the interactive space that is generated by reciprocal communication. It is a relational space that happens with the event of this communication and, together with it, disappears. The place and duration are contingent and unforeseeable. (Cavarero 2005, pp. 204-205) 
The absolute local emerges therefore in the contingent context of interaction, through which we articulate not only our political demands as content, but also in the saying of these demands, reveal something of who each of us is. Thus, to some degree, what Cavarero is after here is reconnecting politics to speech in such a way that it is the action of the speaking subject which matters-for it is actors and speakers (even if they are not "authors") who begin new things in the world, not speech itself.

Politics on this account extends Arendt's views into contemporary discussions about the nature of the political in a globalized world. Unlike many who seek to think through the lens of an ontology of diversity (along the lines that the educational documents suggested above), Cavarero chooses to chart a different course and navigates between the rocky particularist shore of identity politics and the boundless universal sea of rational, discursive communication as models for democracy. The one, she claims, reduces uniqueness to attributes of social positioning, the other, relegates uniqueness-which is a presence not reducible to what one says- to the incommunicable. Both, in her view, depoliticize the space of plurality. I quote her at length:

The politics of the local... avoids imposing cultural identities on the unrepeatable uniqueness of every human being. Because it is faithful to the ontology of plurality, the local puts in play uniqueness without belongings and entrusts the sense of the relation to this alone. And this, in addition to evoking a passivity, implies first of all the preliminary activity of stripping ourselves of our western, eastern, Christian, Muslim, Jew, gay, straight, poor, rich, ignorant, learned, cynical, sad, happy-or even guilty or innocent-being. Indeed, the politics of the absolute local includes as a preliminary act the deconstruction of belongings, the marginalization of qualities, and the depoliticization of the what. What remains, because it was always there, is the question 'who are you?' addressed to the 'you who are here.' This local, contextual space-which can be actively inaugurated anyway-is opened by this question in which the regulative principle of politics already resounds-namely, the priority of the who with respect to the what. (Cavarero 2005, p. 205)

Although Cavarero does not address directly how the absolute local deals with the inevitable conflicts that surface in contexts of plurality, I think the idea of the "priority of the who with respect to the what" enables a better understanding of what is at stake when such conflicts do arise. If the political is a space where uniqueness both appears and is disclosed, then our attention to conflict must be committed politically to the vicissitudes and vulnerabilities inherent in this space. With this in mind, I turn to some concluding thoughts on how an ontology of plurality can reframe democratic possibilities in education.

\section{Education and Democratic Plurality: Redrawing the Boundaries}

Redrawing the boundaries of democratic plurality means having to reframe both the ways in which we talk about diversity, and the focus we place on the political aspects of those relational spaces we engage in our classrooms. As we have seen in the Council of Europe documents cited at the beginning of this paper, diversity begins with an understanding of the subject as one defined through identifiable cultural attributes. Conflicts arising between us are thus thought remediable through recourse to dialogue, which presumably would uncover the cultural biases, prejudices, values and norms which kick off and prolong them. The democratic vision one finds in these documents understands persons abstractly, that is, as functions of their cultural environment. What I have explored here is an alternative 
conception of plurality, one that seeks to put flesh and blood men and women at the heart of political practices.

Unlike the ontology of diversity focus, an ontology of plurality, following Arendt and Cavarero, "has nothing to do with the theme of pluralism, which arises from the question of communitarian identities" (Cavarero 2005, p. 191); instead it is uniqueness in plurality upon which a democratic political project rests. Such uniqueness is not to be confused with the legendary "abstract individual" of liberalism, of which, of course, Arendt was highly critical. Her conception of uniqueness rather is about the specificity of interaction through which one's being appears to others. In this respect, the contextual and contingent nature of that appearance is opposed to the universal subject of liberalism that insists on generalizations for its democratic politics. Introducing an ontology of plurality into a conception of democracy means rethinking the relationship between democracy and education in a way that rubs against the views explored in the European documents above.

Focusing on democratic plurality, in the sense that I've examined here, involves creating spaces where the uniqueness and asymmetrical reciprocity of narrative are put into sharper relief. One way this can occur is to move away from the project of dialogue-both because it reduces the individual to social attributes and because it denies the presence of uniqueness. ${ }^{7}$ Creating local spaces in Cavarero's sense allows for a sense of uniqueness to emerge that resists the fixity of social categories. Such local spaces are not inflexible entities, but are fluid spaces of coming together, of becoming enjoined with others in processes of narrative exchange. The formation of these spaces therefore instantiates a shift from fixed community to instances or events of uniqueness. This is not to say that how we interpret the world and others is never inflected by cultural positionings, but that this is neither the purpose nor the substance of communication. Moreover, the contexts in which communication happens can never be monopolized entirely or determined by communitarian belonging. That is, what is political about our interaction (and the conflicts that arise within it) concerns not the different communities we belong to, but the revelation of ourselves as subjects, as unique beings, as we stake our political claims.

Conceiving these spaces along the lines of an ontology of plurality offers us a way of rethinking the vulnerability that inheres in political exchange, and this is extremely important from an educational point of view, I believe. By disclosing myself, I expose myself to others. I appear before others as a 'who' who does not always know herself who she is. That antagonisms erupt and can be felt so acutely is, in my view, neither due to the failure of the rules of dialogue, nor to the failure of others to understand me. Rather, it has to do with the force of the back-and-forth narrative trajectory through which I can become stranger to myself at the same time as I reveal myself as one who is unique. What is required in educational projects that seek to deal with injustices and the freedom of individuals through democratic and political frameworks is a sensitivity to this very vulnerability and exposure, to what a narrative encounter can 'do' to a subject. As it now stands, intercultural education exacerbates the problem of equality, precisely because it does not have a framework for thinking through the difficulties that inhere in our relational, political spaces. And this means that so long as individuals experience themselves and others as "reducible" to social and cultural attributes, they lack the potential for dealing with the sometimes very difficult and painful aspects of conflict on political terms. That is, if democratic politics is about erasing social and cultural conflict, then it leaves what in fact is political about our relations out of the picture altogether.

\footnotetext{
7 See Todd (2009) and Todd and Säfström (2008) for a more fulsome discussion of the limits of democratic dialogue in education.
} 
Finally, and most importantly, I think redrawing the boundaries of democratic plurality along the lines I've expressed here, offers not so much a space for conflict resolution, or for conflict aversion, but one for conflict articulation. ${ }^{8}$ Conflict articulation provides us with a political framework that focuses on narrative and the necessary exposure of the individual in communicative exchanges. The act of disclosure, as has been already said, is not a question of revealing to others who I think I am, as if I was already a fully formed subject who presents herself to others. Rather, the articulation of myself always requires another who gives back to me my own story. In this, then, conflicts are not so much about positions, perspectives and worldviews, but are articulations that are contested at the very level of who I am. This means that using the language of conflict articulation, instead of resolution or aversion, resituates each of us as someone who is always already implicated in any conflict that arises with others. And is implicated deeply. Thus it is not about getting our communication "right" (through rational dialogue and observance of the ethical rules of discourse) but learning to accept that our conflicts are narrated in ways that also reveal the uniqueness of the one who speaks-beyond, we might say, the borders of cultural diversity. Thus conflict is not simply about conflicting cultures, clashing civilizations or competing worldviews; it is, rather, about each one's own efforts to narrate oneself in relation to others beyond the cemented borders of cultural identity. Redrawing the boundaries of democratic plurality along these lines means that who we are-in all its contingency-just might begin to matter more than what we are.

\section{References}

Arendt, H. (1959). The human condition. New York: Anchor Books.

Arendt, H. (1978). The life of the mind. New York: Harcourt.

Arendt, H. (2005). The promise of politics. New York: Shocken Books.

Batelaan, P. (2003). Intercultural education in the 21st century: Learning to live together. Council of Europe Standing Conference of European Ministers of Education. MED21-5.

Biesta, G. (2010). How to exist politically and learn from it: Hannah Arendt and the problem of democratic education. Teachers College Record, 112(2), 556-573.

Bourquin, J.-F. (2003). Violence, conflict and intercultural dialogue. Strasbourg: Council of Europe.

Cavarero, A. (2000). Relating narratives: Storytelling and selfhood (P. A. Kottman, Trans.). London: Routledge.

Cavarero, A. (2005). For more than one voice (P. A. Kottman, Trans.). Stanford, CA: Stanford University Press.

Council of Europe. (2007). Religious diversity and intercultural education: A reference book for schools. Strasbourg, France: Council of Europe.

Dewey, J. (1966 [1916]). Democracy and education. New York: Free Press.

Leclerq, J.-M. (2002). The lessons of thirty years of European co-operation for intercultural education. Council of Europe Steering Committee for Education. DGIV/EDU/DIAL (2002) 8.

Levinas, E. (1998 [1974]). Otherwise than being or beyond essence (A. Lingis, Trans.). Pittsburgh, PA: Duquesne University Press.

Levinson, N. (2001). The paradox of natality: Teaching in the midst of belatedness. In M. Gordon (Ed.), Hannah Arendt and education (pp. 11-36). Boulder, CO: Westview Press.

Mouffe, C. (2005). On the political. London: Routledge.

Todd, S. (2009). Toward an imperfect education: Facing humanity, rethinking cosmopolitanism. Boulder, CO: Paradigm Publishers.

Todd, S., \& Säfström, C. A. (2008). Democracy, education and conflict: Rethinking respect and the place of the ethical. Journal of Educational Controversy, 3(1). http://www.wce.wwu.edu/Resources/CEP/ eJournal/.

${ }^{8}$ I want to thank David Hansen for suggesting this term to me. It has helped enormously in rethinking the focus of my recent work. 
Copyright of Studies in Philosophy \& Education is the property of Springer Science \& Business Media B.V. and its content may not be copied or emailed to multiple sites or posted to a listserv without the copyright holder's express written permission. However, users may print, download, or email articles for individual use. 